\title{
Peculiarities in Leidenfrost water droplet evaporation
}

\author{
Tadeusz Orzechowski ${ }^{1}$ (1)
}

Received: 7 November 2019 / Accepted: 15 September 2020 / Published online: 1 October 2020

(C) The Author(s) 2020

\begin{abstract}
The investigations involved a large water droplet deposited on the heating surface, the temperature of which was higher than the Leidenfrost point. The main element of the experimental setup was the heating cylinder with K-type shielded thermocouple located in its centre just below the surface. The measuring system was located on highly sensitive scales. The analysis of the droplet behaviour in time was conducted based on measured droplet mass changes over time and also photographic data recorded with high resolution digital camera. The energy balance equation is given for the assumption that evaporation from the droplet upper surface is small compared with the amount of heat dissipated from the bottom surface. The formula for the heat transfer coefficient depends on two slope values and an orthogonal projection of the drop onto the heating surface. The slopes are estimated based on the droplet diameter linear time dependence and mass versus the contact zone relationship. The solution provides a good representation of droplet evaporation under Leidenfrost conditions. The investigations, reported in the study, which concern water droplet at atmospheric pressure deposited on a hot surface with the temperature higher than the Leidenfrost point, indicate the following regularities: droplet orthogonal projection onto the heating surface changes linearly with the droplet mass, evaporation of the same amount of mass decreases linearly with an increase in the heating surface temperature, slope of the graph showing mass loss versus the heating surface temperature successively decreases.
\end{abstract}

Keywords Leidenfrost droplet $\cdot$ Instantaneous mass $\cdot$ Area evolution $\cdot$ Heat balance $\cdot$ Mass-area regularities $\cdot$ Mass loss over time

\author{
Nomenclature \\ A Droplet perpendicular projection $\left(\mathrm{m}^{2}\right)$ \\ a Intercept \\ $b \quad$ Slope \\ $n \quad$ Exponent \\ $c_{p} \quad$ Specific heat $(\mathrm{J} / \mathrm{kgK})$ \\ $H_{f g} \quad$ Phase change enthalpy $(\mathrm{J} / \mathrm{kg})$ \\ $h \quad$ Heat transfer coefficient $\left(\mathrm{W} / \mathrm{m}^{2} \mathrm{~K}\right)$ \\ $K \quad$ Constant defined in the text $(\mathrm{J} / \mathrm{kgK})$ \\ $M_{0} \quad$ Initial mass flux $\left(\mathrm{kg} / \mathrm{m}^{2} \mathrm{~s}\right)$ \\ $m \quad$ Mass $(\mathrm{kg})$ \\ $R^{2} \quad$ Coefficient of determination \\ RSME Residual standard error \\ $T \quad$ Temperature $\left({ }^{\circ} \mathrm{C}\right)$ \\ $t \quad$ Time (s) \\ $\delta \quad$ Height (m) \\ $\nabla \quad$ Regular residuals
}

Tadeusz Orzechowski

todek@tu.kielce.pl; https://orcid.org/0000-0002-1727-8186

1 Kielce University of Technology, Al. Tysiąclecia PP 7, 25-314 Kielce, Poland

\section{Subscripts \\ $D$ Droplet \\ $s \quad$ Saturation \\ $w$ Wall \\ $0 \quad$ Initial}

\section{Introduction}

Boiling is a complex thermodynamic transformation, in which convection and multiphase flow phenomena occur in parallel. It has been used by humans for cooking food since the old days. However, it was only in 1756 that a German physician and theologist Johann Gottlob Leidenfrost paid attention to one particular feature of the process. He described the behaviour of a liquid droplet placed on the surface at sufficiently high temperature. Under such circumstances, the droplet levitates on a vapour cushion it generates. The minimal surface temperature, at which the phenomenon occurs is called Leidenfrost temperature or point. This temperature is related to the maximum lifetime of the droplet and the minimum heat flux. Such a formulation dictates the temperature measurement. For droplets of the same volume deposited on surfaces 
at different temperature, a dependence is received that describes the total evaporation time as a function of the wall superheat. In other words, superheat is surface temperature surplus over the saturation temperature of the liquid the droplets of concern are made of. The dependence measured in this way is closely related to the boiling curve, which was described by Nukiyama [21]. The same boiling regimes are found there, i.e. convection without change of phase, and also nucleate, transition and film boiling. The extremum of both curves between transition and film boiling ranges is termed as the second critical point, or Leidenfrost point. Although this temperature is well defined, Bernardin and Mudawar [2] pointed out that values found in the literature even for the same liquids deposited on the surfaces of the same material often show substantial differences. In addition, the dependences available for the determination of this temperature produce values that are to a large extent different from the actual ones. That results from the fact that investigations are conducted for droplets that differ in volume [29], initial temperature [45], liquid purity [17], at different values of atmospheric pressure [48]. Differences also concern the substrate material, the mechanical, thermal or chemical treatment applied to it $[14,42]$, which is recently explained by Tabe et al. [38] by the influence of the intermolecular force between liquid and surface molecules and also the substrate orientation in space, i.e. its inclination [32].

Baumeister and Simon [1] related Leidenfrost temperature to thermal conductivity, density, and specific heat of the substrate. Based on experimental investigations into droplets of methanol, ethanol, water and $\mathrm{NaCl}$ solution evaporated from mild steel, aluminium, brass and copper substrates, Mozumder et al. [20] observed that the evaporation of the water droplet is the longest, and $\mathrm{NaCl}$ addition makes it only slightly longer. The shortest evaporation time was found for ethanol and methanol. The relation between the evaporation time of $\mathrm{NaCl}$ solution and the substrate material conductivity was reported. The evaporation time is the highest for good thermal conductivity materials, and the lowest for mild steel, the thermal conductivity of which is decidedly lower. The higher rate of evaporation from the copper surface compared to aluminium is also confirmed by Ye at al. [46] tests. Similar regularities are also found for other liquids. Measured evaporation time is closely related to Leidenfrost temperature, the latter was calculated based on correlations available in literature.

For the substrate made from aluminium, brass, Monel, and stainless steel, Orejon et al. [23] showed that at lower than atmospheric ambient pressure, Leidenfrost temperature value decreases with pressure fall in the manner that follows the simplified Clausius-Clapeyron equation, i.e. 1/TL versus $\log P$.

Burton et al. [4] demonstrated that vapour cushion underneath a large droplet depends on the droplet size, but it is hardly affected by the surface temperature. For large droplets, vapour lingering underneath has the shape of a convex bowl. Due to shape, Biance et al. [3] categorised droplets into two groups: small spherical ones and large cylindrical ones, which they called puddles. The droplet mainly evaporates via the film. Biance et al. reported that the vapour cushion under the water droplet deposited on the duralumin plate kept at high temperature decreases with the droplet size, and the rate of those changes is different for small and large droplets. Roques-Carmes et al. [33] gave similar observations. Quéré [31] estimated a vapor film thickness of $100 \mu \mathrm{m}$. Cai et al. [5] indicate that along with a decrease in the temperature of the heating surface is accompanied by a monotonic decrease in the thickness of the vapor layer under the drop. Based on the lubrication theory, Wua et al. [44] showed that during rotation and translation a thicker layer of vapor forms under the drop compared to the corresponding steady state. Similar conclusions are reached by OK et al. [22]. Lee et al. [11] showed that under dynamic conditions the cushion forms in a very short time and is only tens of micrometers thick. According to Moon et al. [19] additional conditions for such interaction are associated witch changes in liquid viscosity. Qiao et al. [30] numerical research concerned the impact of many parameters on the evolution of drop, including Stefan, Prandtl, Bond and Ohnesorge numbers. In addition according to Limbeek et al. [13] reduction of heat flux value may also be the result of lowered the surface temperature under the drop.

Paul et al. [28] conducted investigations into water droplets at atmospheric pressure that evaporated from the copper surface maintained at temperature of 300,350 and $400{ }^{\circ} \mathrm{C}$. The authors discussed geometry of droplets, variable in time, and devised a formula for droplet orthogonal projection onto the heating surface. The droplet projection formula does not depend on the initial droplet mass, which was confirmed by reported measurements. The proposed dependence was used by Orzechowski [24], who worked out a formula, expressed as infinite series, for droplet mass change over time. The effective application of the formula, however, makes it necessary to individually select coefficients that describe the area of the droplet projection. The coefficients depend on the heating surface temperature, which was also observed by all authors, who stress the necessity of conducting further investigations in this respect. In an earlier study, Orzechowski and Wciślik $[25,26]$ proposed approximation of droplet projection by power series versus time. With such an assumption, the final outcome comes as a relationship for heat transfer coefficient. The investigations reported in the study were conducted for a heating surface with a relatively small curvature radius ( $\sim 64 \mathrm{~mm}$ ), making it impossible to apply them to calculations of heat transfer between the plane and the droplet levitating above it.

The amount of heat transfer depends on the liquid kind, and for mixtures, on their composition. The effect of salt additives 
dissolved in deionized water on heat transfer in spray quenching of aluminium alloy heated to $495^{\circ} \mathrm{C}$ was described by Guo et al. [8]. Among the substances considered, only solution with $\mathrm{MgSO}_{4}$ enhances the heat flux conveyed both in nucleate and transition boiling regimes. The nucleate boiling is most enhanced when $\mathrm{CaCl}_{2}$ is added, while the solution with $\mathrm{NaCl}$ produces the least enhancement. On the example of $\mathrm{LiBr}$ and $\mathrm{CaCl}_{2}$ salts, Misyura [15] demonstrated that an increase in salt concentration leads first to rise and then to fall in the proportion of convective flux during evaporation, compared with the diffusive one. Similar conclusions can be found in a later study by this author [16]. Chen et al. [6] showed a substantial increase, amounting up to $65{ }^{\circ} \mathrm{C}$, in dynamic Leidenfrost temperature due to high-alcohol surfactants additives (octanol and ethylhexanol) to water droplets. The phenomenon was attributed to surface tension reduction. Using an example of droplets of non-Newtonian fluid, which is a mixture of water and xanthan gum, Moita et al. [18] indicated a strong relationship between heat transfer and flow dynamics, and its weak dependence on viscosity. Similar effects are found for nanofluids (e.g. [40, 43, 47]), and are produced by surfactants (e.g. Kang et al. [9]). For binary surfactant mixtures Sarkar and al. [34] reports an increase in the cooling rate of steel surfaces with temperatures above $900{ }^{\circ} \mathrm{C}$ up to almost $70 \%$ compared to pure water.

The rate of evaporation is greatly affected by metallic additives. Legros and Piskunov [12] discussed the effect produced by seven different additives on the lifetime of droplet placed in a hot gas flux, the temperature of which ranged from 300 do $900{ }^{\circ} \mathrm{C}$. Droplet lifetime decreases with an increase in thermal conductivity of inclusions.

Levitating under Leidenfrost conditions, the droplet produces vapour on the bottom surface in a continuous manner. As the vapour flows, lift is generated. Depending on the surface morphology, this flow can cause the droplet chaotic motions and shape instability, which directly affects the heat transfer magnitude. Bernardin and Mudawar [2] reported that for polished aluminium, Leidenfrost temperature is approx. $80^{\circ} \mathrm{C}$ higher compared with rough-finished surfaces. In addition to rise in film boiling temperature, Lee et al. [10] observed that transition boiling regime extended, even by $150{ }^{\circ} \mathrm{C}$, on micro/nano multiscale textured surfaces. As claimed by Talari et al. [39], such structures seem the most promising as regards increasing Leidenfrost temperature and making cooling processes more efficient.

Vapour generated under the droplet produces an insulation layer, which substantially reduces the amount of heat carried away. Many studies by Shahriari et al. [35, 36], Ozkan et al. [27] indicate the magnitude of heat transfer is significantly affected by external electrostatic field. The effect of the electrostatic field action manifests itself in changes in vapour layer thickness, which leads to enhanced boiling heat transfer. According to Wang et al. [41], the phenomena result from surface electric charges that alter the interaction between the surface and vapour layer.

Numerous studies that describe various physical processes related to the droplet levitating above a heated surface do not provide sufficient information on the phenomenon. For example, calculation of the amount of heat dissipated by conduction through a thin layer under the drop does not give sufficiently accurate results. By using very accurate measurements of the area of perpendicular projection of drops on the heating surface and assuming only conduction through a layer given e.g. by Biance Biance et al. [3] or more recent studies reported by Dasgupta et al. [7] about 30\% lower necessary time for evaporation of a given amount of mass is obtained.

The heat flux removed from the cooled surface is the result of radiation, convective and conduction through a thin layer of steam under the drop. An additional difficulty is the change of the liquid phase into the gas phase accompanying these phenomena. The aim of this study is to indicate some regularities that accompany Leidenfrost effect and also the fact that the rate of evaporation is the result of specific relationship between the area of orthogonal projection of droplets onto the heating surface.

\section{Experimental set-up}

The experimental set-up, designed to investigate droplet evaporation, included a number of modules that operated autonomously. Simplified diagram of the measurement stand is shown in Fig. 1.

The most important component is the heating module with a system of maintaining stable pre-set surface temperature. Power supply necessary for the system to operate is delivered to $400 \mathrm{~W}$ wrapped heater via a transformer. The admissible temperature of the heater constant operation can be up to $500{ }^{\circ} \mathrm{C}$. Another module is that for recording mass change over time. It is electronic scales with accuracy of $0.01 \mathrm{~g}$ and sensitivity of $0.001 \mathrm{~g}$ as declared by the manufacturer. After the analogue signal is converted to the digital one, it is sent by cable, via RS232 connection to the computer for further analysis. The maximum signal registration frequency is $5 \mathrm{~Hz}$. The temperature measurement module with analogue/digital card connected to the computer is an autonomous operating unit. $\mathrm{K}$-type shielded thermocouples operated as sensors. Compensation wires of thermocouples and also electricity supplying cables were suspended in such a way so that the impact of their weight on the scales reading could be eliminated. Correctness of the assembly was checked after adequate electrical power was supplied, and the system had been conditioned for a few hours. A thermocouple for recording the heating surface temperature was installed in centrally placed opening in such a way so that thermocouple measuring 

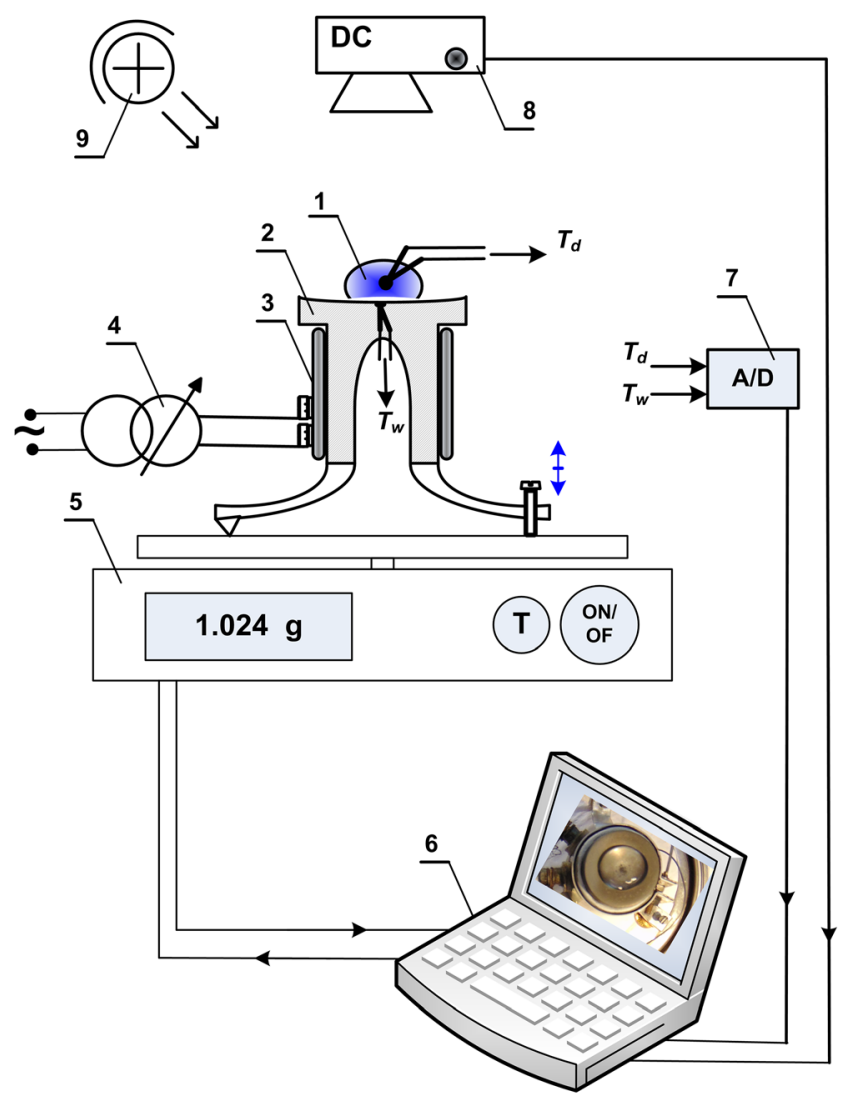

Fig. 1 Diagram of the test apparatus: 1 - droplet of water, 2 - copper cylinder, 3 -wrapped heater, 4 - electric power supply unit (autotransformer), 5 - electronic scales, 6 - computer, 7 - A/D signal processing system 8 - digital camera, 9 - lighting lamp

connection was located approx.1 $\mathrm{mm}$ below the surface of the copper heating cylinder.

For droplet levitating under Leidenfrost conditions, heat transfer proceeds mainly through the droplet bottom part. The measurement of the droplet orthogonal projection onto the heating surface was taken based on photographic data obtained with a $24 \mathrm{Mpx}$ matrix digital camera, suspended directly above the stand. It was essential to record high quality photograph, which was ensured by an independent light source (Fig. 1) emitting a small amount of thermal energy.

On the heating surface, adequately preheated in advance, a water droplet of room temperature was deposited. The droplet central positioning during the tests was ensured by the semi-spherical shape of the upper surface. The depth of the latter, measured from the $45 \mathrm{~mm}$ diameter base, is approx. $1 \mathrm{~mm}$. In addition, all the components were carefully levelled.

Calibration measurements conducted earlier showed that the droplet got hot very fast, whereas later on its temperature was almost constant, and only a few degrees higher than the saturation temperature $\left(\sim 96{ }^{\circ} \mathrm{C}\right.$ on average $)$. Therefore, the analysis of the measurement always started after a while (usually after minimum $10 \mathrm{~s}$ ).
A detailed description of the measurement procedure can be found in the papers of Orzechowski and Wciślik [25, 26].

\section{Procedure}

The stiffness of suspended electricity cables and thermocouple wires is altered due to temperature. The effect of changes in wire elasticity on the readings of very sensitive scales was eliminated by means of the setup conditioning. The electric heaters maintaining pre-set surface temperature were switched on a few hours before the start of the experiment. At a pre-set heating surface temperature, above the Leidenfrost point, a deposited water droplet evaporated in the film boiling regime. The measurement results came in the form of droplet mass change over time, an exemplary illustration of which is shown in Fig. 2.

The mean value of the heating cylinder temperature was $\mathrm{T}_{\mathrm{w}}=325^{\circ} \mathrm{C}$. As regards droplets with large mass, different types of instabilities were found, which results from complex convective motions inside the droplet. For instance, bubbles that grow and depart can be observed. Formation of nucleation sites and bubble growth are characteristic of droplets with relatively high mass. Emerging bubbles produce a vapour cushion under the droplet and escape as a gas "chimney" [37]. The vapour cushion growth changes the shape of the droplet orthogonal projection, making it irregular. Additionally, the time of droplet residence below the surface is not the same. Figure 3 shows lifetimes of exemplary droplets with the initial mass of $2.031 \mathrm{~g}$ and $1.823 \mathrm{~g}$, which are approx. $8 / 30 \mathrm{~s}$, and $17 / 30 \mathrm{~s}$, respectively. Similar analyses conducted for a larger number of cases did not show a relationship between droplet lifetime and the surface temperature. For the droplet mass close to that given in Fig. 3a and b, emerging droplets vanish already within about $2 / 30 \mathrm{~s}$. The

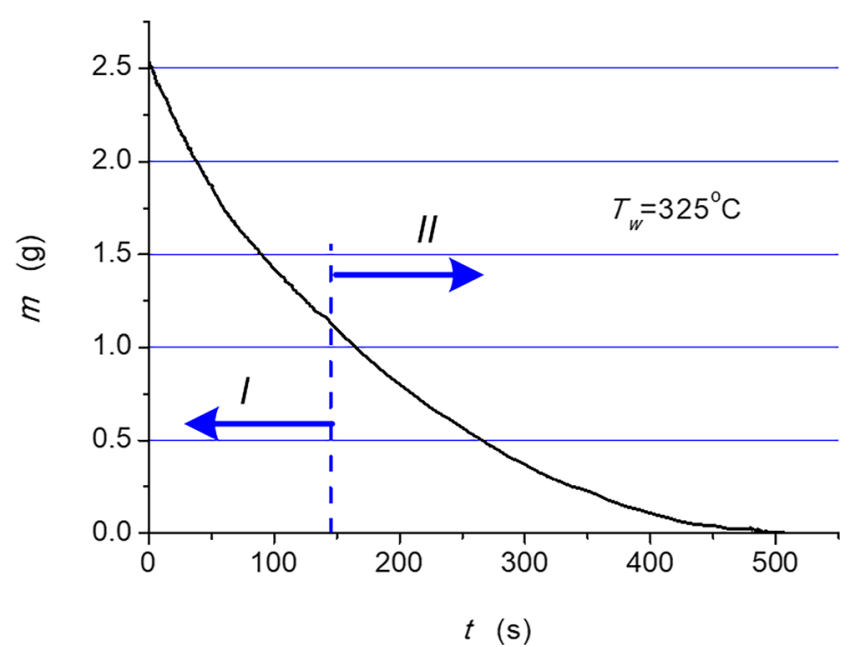

Fig. 2 Water droplet evaporation from the wall with temperature of $T_{w}=$ $325^{\circ} \mathrm{C}$ : I - vapour bubble occurrence, II - stable zone 
Fig. 3 Droplet shape evolution at various stages of evaporation acc. Figure 2. Shapes shown every: (a) $1 / 15 \mathrm{~s}$, (b) $1 / 6 \mathrm{~s}$, (c) $1 / 15 \mathrm{~s}$, (d) $10 \mathrm{~s}$, respectively a)
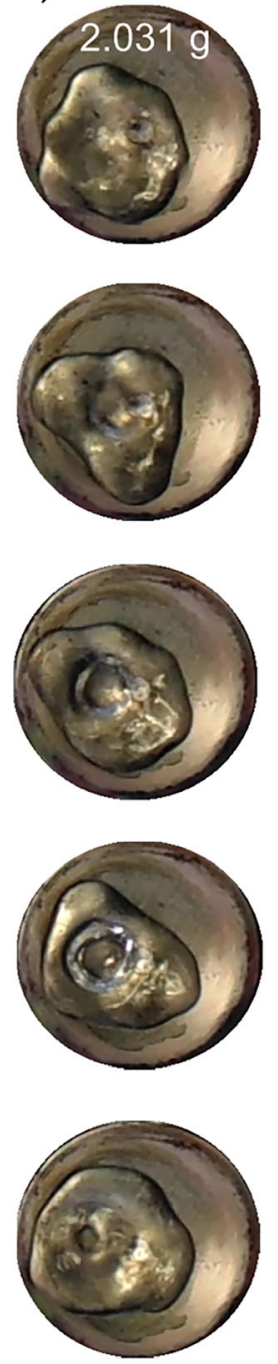

b)


c)
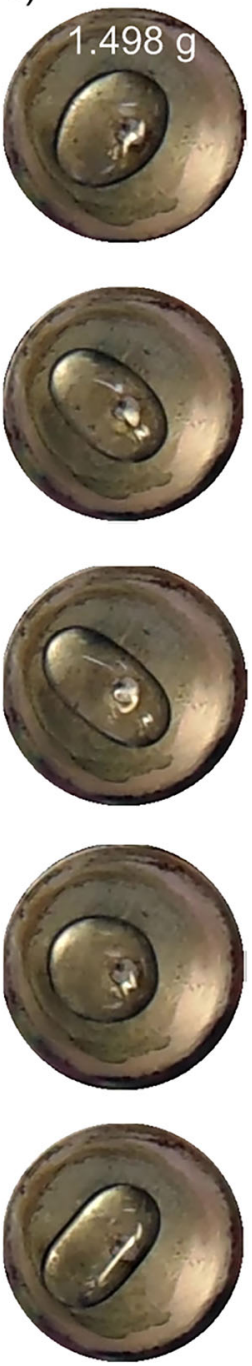

d)
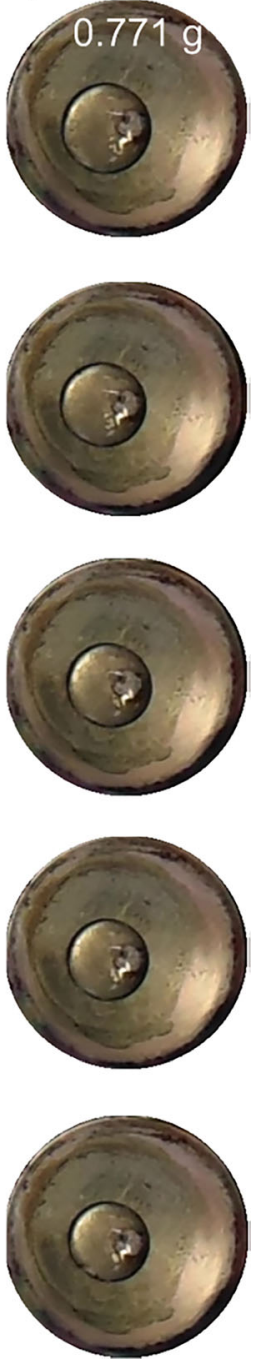

phenomenon occurs for the droplet mass above $\sim 1.116 \mathrm{~g}$. Below that value, the disturbances tend to terminate. The observed boundary at which vapour bubbles underneath the droplet vanish corresponds to findings reported in Biance et al. [3]. Further on, a droplet is observed, the shape of orthogonal projection of which onto the heating surface shows a close resemblance to a circle (Fig. 3d). Slow disappearance of subsurface generation of bubbles is observed as well. Already with the droplet mass of approx. $1.5 \mathrm{~g}$, if bubbles emerge at all, they are much smaller and reside inside the droplet. Then, they disappear after subcooling. The evolution from intensive to stable vapour bubble generation is characterised by great instability in the droplet shape and position, as shown in Fig. $3 \mathrm{c}$. This is the transition range. In this case, droplets take on the shape of a cylinder, laid on the side, with the base assuming a shape of a flattened ellipse. Additionally, when performing a swinging motion, such objects slightly alter the location of the system centre of mass. That is manifested as changes in weight that can be seen over the end of zone I (see
Fig. 2). For small droplets $(m<0.9 \mathrm{~g})$, the scales readings do not show local fluctuations, and the droplet projection on the heating surface takes on a stable circular shape. In Fig. 3d, a series of droplets is presented. The first one has a mass of $0.771 \mathrm{~g}$. All the subsequent ones, recorded at equal time intervals of $10 \mathrm{~s}$, have a regular circular shape when projected onto the heating surface.

Forms of droplets, illustrated in Fig. 3, evaporating from the surface, the temperature of which is higher than the Leidenfrost point, are not the only ones that can be found. In some series, complex shapes, like star patterns, can be seen. Their occurrence, however, does not produce clear changes in the mass recorded by the scales. Disturbances are observed only in situations, when the droplet is upset and shifted from its central position. That results in instantaneous balance loss related to the device inertia. The phenomena described above could be confirmed by the dependence of evaporated mass flux on time, as shown in Fig. 4. The graph originates from numerical differentiation of the data shown in Fig. 2. 


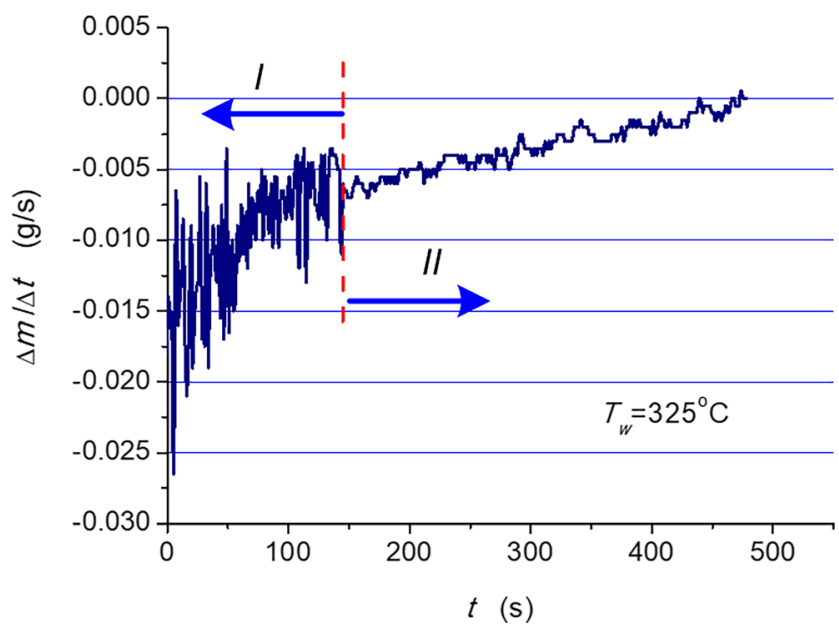

Fig. 4 Changes in the mass flux during evaporation from the droplet according to Fig. 2

A similar relation holds for the area of the droplet orthogonal projection onto the heating surface. Figure 5 shows the area as a function of time. The area was calculated on the basis of selected frames of the footage recorded using the digital camera located directly above the droplet.

For large droplets, fluctuations in the area of the droplet orthogonal projection are observed. The area grows with an increase in the volume of remaining vapour and decreases abruptly just after the bubble is released. Comparison of data in Figs. 2, 3, and 5 provides an illustration of the trends mentioned above.

Figure 6 shows the graph of the area of the droplet orthogonal projection as a function of mass. The initial mass of the droplet was $m_{0} \approx 2.5 \mathrm{~g}$, and the heating surface temperature was $T_{w} \approx 325^{\circ} \mathrm{C}$. The relation is linear.

The accuracy of approximation of experimental data can be evaluated by computing regular residuals $\Delta$ for each measurement. Here, regular residual is defined as the difference between the measured area of the orthogonal projection $A$ and

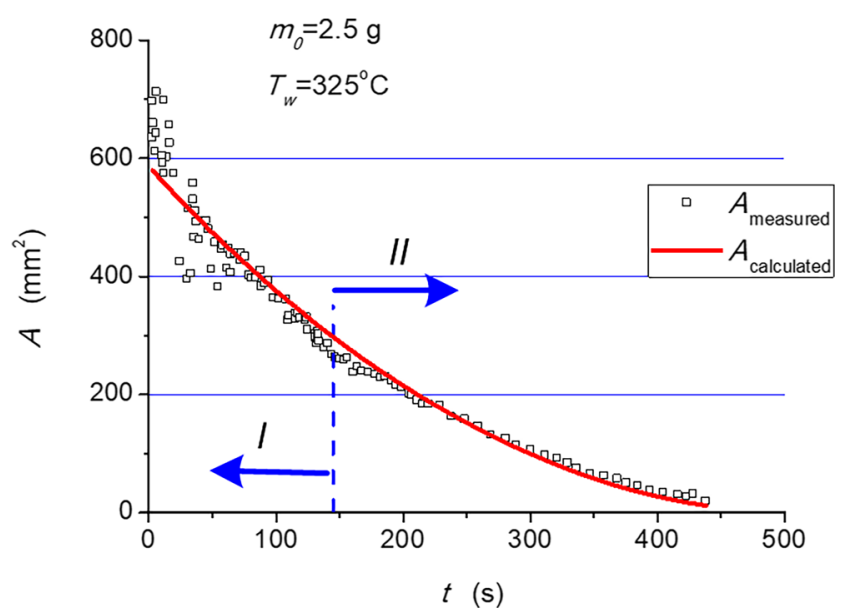

Fig. 5 The area of the droplet orthogonal projection onto the heating surface as a function of time

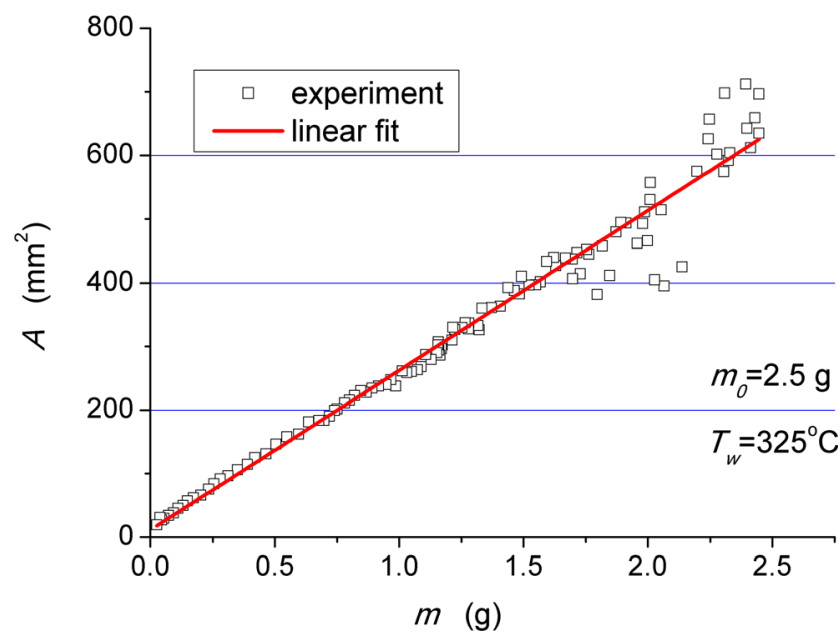

Fig. 6 The area of the droplet orthogonal projection onto the heating surface as a function of the droplet mass

the value computed using the straight-line equation $A_{\text {liner }}$ for the same droplet mass, as shown in Fig. 7.

Discrepancies from the linear dependence of droplet projection on mass are the highest for large droplets. As indicated earlier, that is caused by generation, subsurface residence and departure of vapour bubbles. In the graph, in addition to the zones described earlier, an additional one, namely transition zone III (ranging from approx. 0.89 to $1.5 \mathrm{~g}$ ) can be identified. Instabilities in readings of the scales result from changes in the droplet shape, and the displacement of the droplet centre of mass.

The droplet undergoes rotation as it travels over the surface. The centrifugal force that appears due to rotation causes a change in the droplet shape. In this range, the shape takes on the form of stretched ellipse. Consequently, the droplet becomes flattened and the area of its orthogonal projection slightly increases. As a result, small deviations from the linear relation between area and mass are found. The magnitude of deviations can be evaluated on the basis of Fig. 3 .

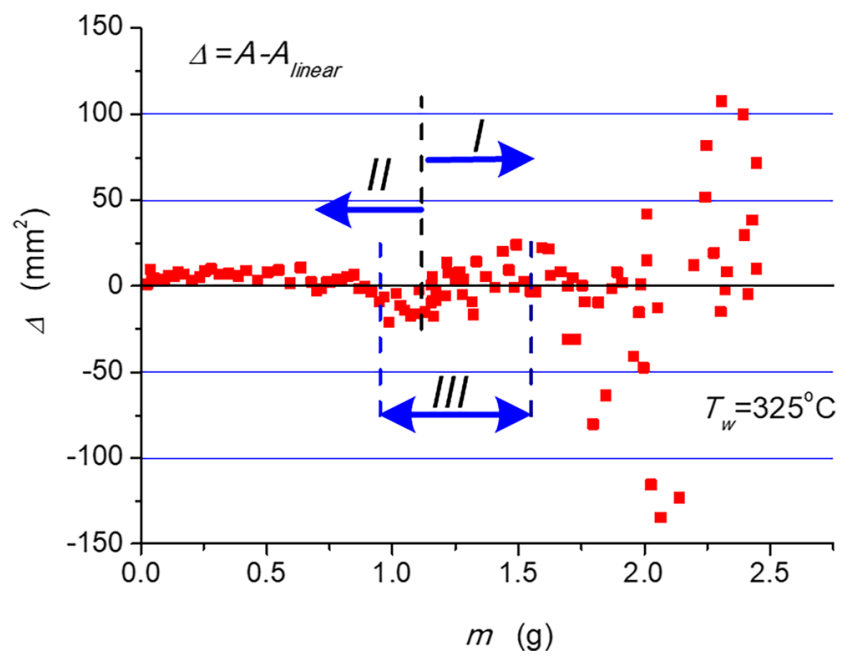

Fig. 7 Regular residuals versus droplet mass 


\section{Heat transfer analysis}

Evaporation of the droplet levitating above a hot surface is an extremely complex process, in which the phenomena of heat and mass transfer coincide. However, the greatest portion of heat transfer proceeds between the heating surface and the droplet bottom. If evaporation from the droplet upper surface is assumed to be small compared with the amount of heat removed carried away from the bottom surface, and overall heat transfer coefficient contains all heat transfer components, heat balance can be written as below. In the formula, change of droplet mass $m$ over time $t$ is implied:

$h\left(T_{w}-T_{d}\right) A=-\left(c_{p}\left(T_{s}-T_{d}\right)+H_{f g}\right) \frac{d \mathrm{~m}}{\mathrm{~d} t}$

where $T_{w}, T_{d}$ and $T_{s}$ are surface, droplet and saturation temperatures, respectively, $A$ - the droplet orthogonal projection onto the heating surface, $c_{p}$ - specific heat, and $H_{f g}-$ phase change enthalpy at the saturation temperature, here, at atmospheric pressure.

The left-hand side of the Eq. (1) is the heat transferred by convection from the bottom surface of the droplet. The first term of right-hand side of the equation shows the heat necessary to heat up the liquid from the droplet temperature to the saturation temperature. The other term of the right-hand side of the equation describes the amount of energy necessary for liquid-to-gas phase change.

From Fig. 6 follows that linear dependence holds between the area $A$ and the droplet mass $m$ :

$m=a_{m}+b_{m} A$

where $a_{m}$ and $b_{m}$ represent intercept and the straight-line slope, respectively.

To obtain solution to Eq. (1), it is necessary to provide a correlation for droplet projection onto the heating surface. Various approximation functions for this quantity are found in the literature. The study [28] reported investigations into water droplets, 1, 2 and $3 \mathrm{ml}$ in volume, deposited on the copper surface at the temperature of 300,350 and $400{ }^{\circ} \mathrm{C}$. The results indicate evaporation duration exponential dependence on time. The exact formula for this dependence was given only for the surface temperature of $400{ }^{\circ} \mathrm{C}$. In the paper conclusions, the authors postulated linear dependence between droplet lifetime and its initial volume and inversely proportional relation between droplet lifetime and temperature. In the study [24], it was shown that in order to apply this dependence for different parameters, is it necessary to choose the base of power on case-by-case basis. That additionally makes it difficult to apply the formula for general use.

It is extremely hard to provide a theoretical description of the behaviour of a droplet levitating above the hot surface. A floating droplet does not always take a regular shape. With their large mass, usually over $1 \mathrm{~g}$, subsurface bubbles are observed, which largely cause a variable shape of a statistical nature. However, the dependence for the orthogonal droplet projection onto the heating surface shown in Fig. 5 indicates the occurrence of some kind of functional relation that can be approximated with a power series. Such a procedure was adopted for the data in Fig. 5 using the criterion of Mean Squared Error (MSE). The best approximation was obtained with second order polynomial, for which Residual Standard Error (RMSE) was $39.7 \mathrm{~mm}^{2}$. The comparison of experimental data with their polynomial approximation indicates that the values originating from the beginning of the process have the largest share in RSME. The respective analysis of a droplet with the mass below $1.9 \mathrm{~g}$ yields an error that is half lower, i.e. for $m<1.9 \mathrm{~g} R S M E=18.1 \mathrm{~mm}^{2}$.

In study [3], power dependence for the radius of the droplet contact zone area on time was put forward. The droplet projection onto the surface is not always circular, therefore in this study a modified form of this dependence, i.e. a function of time, is proposed:

$A=A_{0}\left(1-\frac{t}{t_{0}}\right)^{n}$

where $A_{0}$ is the area of the contact zone of the droplet with mass $m_{0}$ at the initial instant, $t_{0}$-droplet lifetime, $n$ - exponent selected on case-by-case basis (here $n=2$ ).

By inserting (2) and (3) into the heat balance (1) and after its integration, we get the following relationship representing the coefficient of heat transfer between the bottom of the drop and the heating surface:

$h=\frac{2 K b_{m}}{t_{0}\left(1-\frac{t}{t_{0}}\right)}=\frac{2 K b_{m}}{t_{0}} \sqrt{\frac{A_{0}}{A}}=\frac{\sqrt{\pi K b_{D} b_{m}}}{\sqrt{A}}$

where $b_{A}-$ slope (acc. Eq. 6), the parameter $\mathrm{K}$ is given by the formula:

$K=\frac{H_{f g}+c_{p}\left(T_{l}-T_{d}\right)}{T_{w}-T_{d}}$

The formula for the droplet contact zone area (3) entails a linear relationship between diameter $D=2 \sqrt{A / \pi}$ and time. The values produced by this relationship for all points from Fig. 5 are shown in Fig. 8.

The relationship mentioned above can be written as follows:

$D=D_{0}-b_{D} t$ 


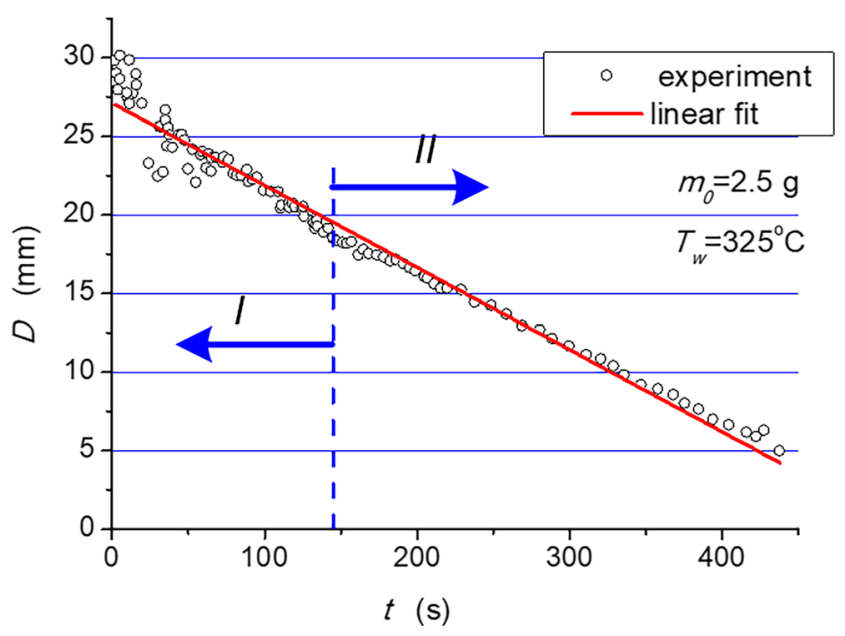

Fig. 8 Calculated droplet diameter as a function of time

where $D_{0}$ is the equivalent diameter of a circular droplet with the area of $A_{0}$, and $b_{D}$ is a slope of a linear fit of the data in Fig. 8, for which $R M S E=1.02 \mathrm{~mm}$. As regards the droplet with the mass $\mathrm{m}<1.9 \mathrm{~g}$, the error is accordingly lower $(R M S E=0.62 \mathrm{~mm})$.

It is often difficult to precisely measure the lifetime $t_{0}$ of a droplet levitating above the hot surface. The reason lies in the droplet unstable behaviour leading to momentary contacts with the surface, which accelerates the evaporation. It is more convenient to determine the slope of the fitting line, as a result the lifetime found in formula (4) is expressed as $t_{0}=D_{0} / b_{D}$.

\section{Measurement uncertainty}

The result of the research is the heat transfer coefficient that changes with the droplet size. It is calculated according to the relationship (4), with the use of which the following formula for relative uncertainty was determined:

$\frac{\Delta h}{h}=\frac{\Delta b_{D}}{b_{D}}+\frac{3}{2} \frac{\Delta b_{m}}{b_{m}}+\frac{1}{2} \frac{\Delta m+\Delta a_{m}}{m-a_{m}}$

where $b_{D}, b_{m}$ and $a_{m}$ (acc. Eqs. 2 and 3) are linear regression coefficients determined on the basis of data presented in Figs. 6 and 8 respectively and $\Delta b_{D}, \Delta b_{m}, \Delta m, \Delta a_{m}$ their standard errors.

For commercial purposes, accuracy of scale indications is determined in stationary conditions using standard weights. Here, due to the non-stationary change in the evaporating mass of the droplet, this value should be determined individually during calibration measurements. For this purpose, several series of the droplet mass change were registered at the set temperature of the heating surface. On this basis, the standard deviation was calculated, which in the accuracy analysis was taken as a mass measurement error.
Table 1 gives values used to calculate the measurement uncertainties according to (7), which are shown in Fig. 9.

In the case of droplets with an initial mass of about $2.5 \mathrm{~g}$, subsurface formation, growth and release of steam bubbles are observed in the initial evaporation period, resulting in changes in the perpendicular droplet projection onto the heating surface (see Fig. 6). As the mass decreases, the frequency of bubble formation decreases, and the shape of the drop tends to oval (see Fig. 7). For this reason, the standard errors of both slope and intercept are greater at $m_{0}=2.5 \mathrm{~g}$ compared to the corresponding errors for $m_{0}=1.9 \mathrm{~g}$. In the first case, the maximum relative uncertainty is $\sim 9 \%$ in the range from $2.5 \mathrm{~g}$ to about $0.2 \mathrm{~g}$. Accordingly, it is lower than $5 \%$ in the range from $1.9 \mathrm{~g}$ up to $0.2 \mathrm{~g}$, as shown in Fig. 9 .

From the relationship (4), the values of the heat transfer coefficient and the standard error range were calculated due to measurement uncertainties. It takes on different instantaneous values that are burdened with variable error, which is shown in Fig. 10.

\section{Results and discussion}

Evaporation of a droplet levitating above the heating surface is discussed in Chapter 4 for the exemplary surface temperature of $T_{w}=325{ }^{\circ} \mathrm{C}$. To confirm the properties of the process, a large number of measurements was taken for different heating surface temperatures ranging from 300 to $400{ }^{\circ} \mathrm{C}$. Exemplary measurement results are shown in Fig. 11. Due to bubble generation at droplet mass greater than $1.7 \mathrm{~g}$, the experimental range was limited to $\mathrm{m}<1.9 \mathrm{~g}$.

The values of intercept $a$ and slope $b$, determined after linear approximation performed acc. Figure 11, are: $a=$ $17.17 \mathrm{~mm}^{2}$ and $b=256.04 \mathrm{~mm}^{2} / \mathrm{g}$. Coefficient of determination of the straight line to measurement results is very high and equals 0.9825 . On this basis, general assumption can be adopted that the area of orthogonal projection of a large

Table 1 Measurement values and corresponding uncertainties

\begin{tabular}{lll}
\hline$m_{0}<1.9 \mathrm{~g}$ & $T_{w}$ & $325{ }^{\circ} \mathrm{C}$ \\
\hline$A=a_{m}+b_{m} m$ & $R^{2}$ & 0.9884 \\
& $a_{m}$ & $19.25 \mathrm{~mm}^{2}$ \\
& $\Delta a_{m}$ & $3.21 \mathrm{~mm}^{2}$ \\
& $b_{m}$ & $242.19 \mathrm{~mm}^{2} / \mathrm{g}$ \\
$D=D_{0}-b_{D} t$ & $\Delta b_{m}$ & $2.83 \mathrm{~mm}^{2} / \mathrm{g}$ \\
& $R^{2}$ & 0.9921 \\
Mass & $b_{D}$ & $242.19 \mathrm{~mm} / \mathrm{s}$ \\
& $\Delta b_{D}$ & $4.7 \cdot 10^{-4} \mathrm{~mm} / \mathrm{s}$ \\
\hline
\end{tabular}

Where $R^{2}$ - coefficient of determination 


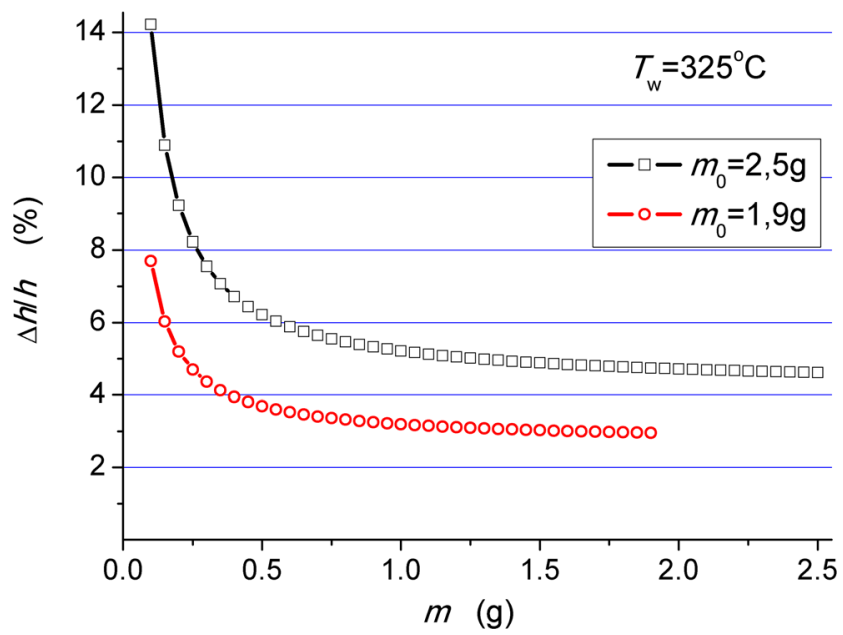

Fig. 9 Relative uncertainty for drops with an initial mass $m_{0}=2.5 \mathrm{~g}$ and $1.9 \mathrm{~g}$ at $325^{\circ} \mathrm{C}$ heating surface temperature

droplet deposited onto a hot surface with the temperature higher than Leidenfrost point changes in a linear manner with its mass. Additionally, that is independent of the heating surface temperature.

The quality of linear approximation can be evaluated when approximation errors are calculated for each of measured points. For the set obtained in this way, RSME was calculated, which equals $17.1 \mathrm{~mm}^{2}$. The highest deviations from the measured values are observed for large droplets. Their areas are enlarged due to the presence of the bubble that is being generated. Conversely, the areas become correspondingly diminished just after the bubble has departed, as seen in Fig. 3b.

As regards small droplets with the mass below $0.2 \mathrm{~g}$, it can be observed that the values of the area of the droplet orthogonal projection tends to decrease successively. The values approach zero (see Fig. 11). That is related to droplet shape which evolves from roughly a flattened disc, for large droplets, to a sphere, for small ones. With small droplets, when their height approaches their diameter, the shape of the vapour

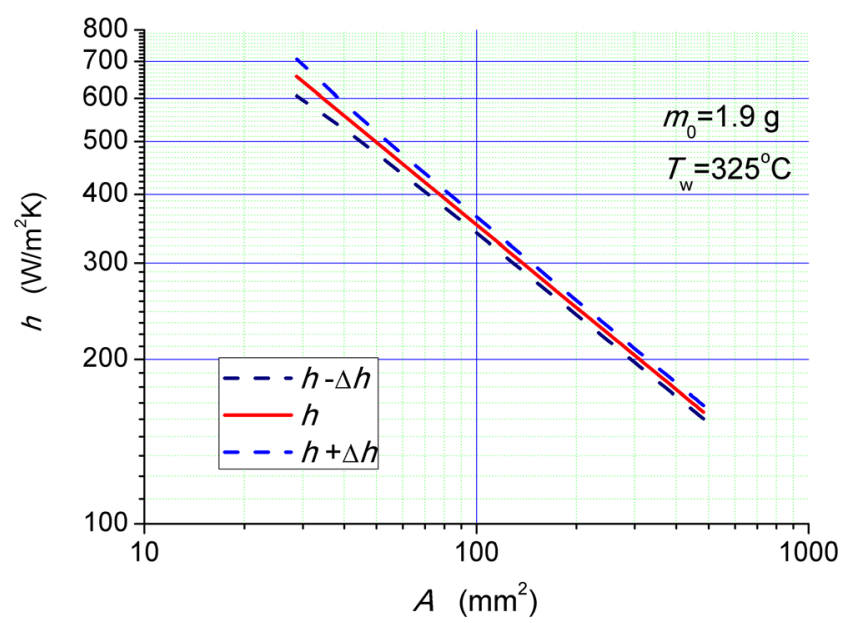

Fig. 10 Heat transfer coefficient (solid line) and its upper and lower error limits (dashed lines)



Fig. 11 Dependence of droplet orthogonal projection on its mass

cushion below the droplet is changed, which affects vapour flow. That calls for a separate analysis.

The droplet height is specified on the basis of the drop surface A, resultant from its projection on the surface, and of the instantaneous drop mass, which can be described by Eq. 8 and is presented in Fig. 12.

$\delta_{d}=\frac{m}{\rho A} \quad$ and $\quad \delta_{d}$ linear $=\frac{m}{\rho(a+b m)}$

where $\rho$ is the fluid density, $a$ is the intercept and $b$ is the line slope.

Dependences (2) and (3) make it possible to calculate the momentary value of mass. For a droplet levitating above the surface with the temperature of $T_{w}=325^{\circ} \mathrm{C}$ and $\mathrm{m}<1.9 \mathrm{~g}$, the exemplary curve determined as above is shown in Fig. 13. Intercept $a$ and slope $b$ in formula (2) were adopted according to linear approximation taking into account all measurements shown in Fig. 11.

Momentary differences between measured values of the droplet mass and the calculated ones are shown in Fig. 14.

The differences are the greatest at the beginning, when bubble generation is observed below the droplet, and also at

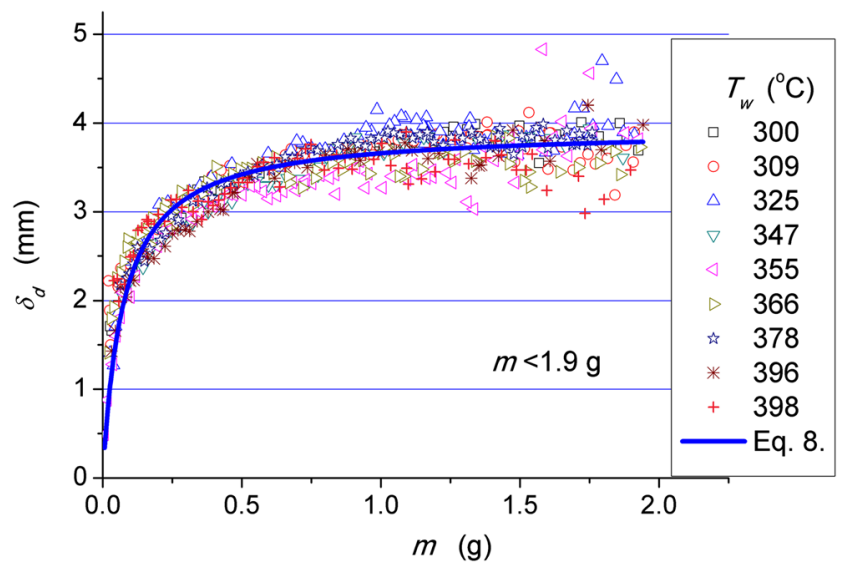

Fig. 12 Droplet height: from the experiment (scatters) and calculated acc. linear fit of $A$ (solid line) 


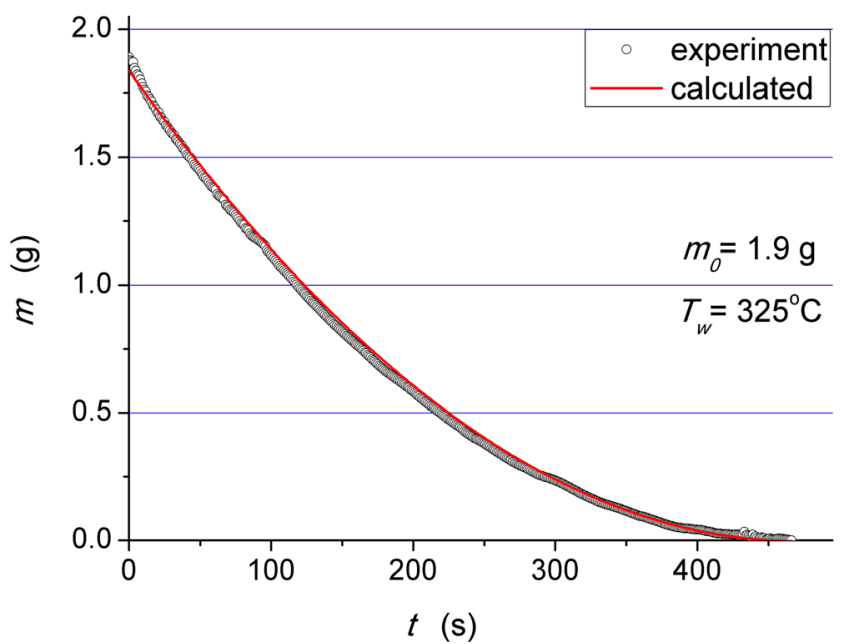

Fig. 13 Measured and calculated change in the droplet mass in time

the final stage when the orthogonal projection area deviates from a linear dependence determined in Fig. 6. As indicated in Fig. 14, residual standard error is $\mathrm{RSME}=0.022 \mathrm{~g}$ and it remains within the range of the scale accuracy. Greater differences between measured and calculated values are found at the initial and final stages of the droplet lifetime. That is confirmed by the phenomena related to the vapour bubble generation below droplets, discussed earlier, and also by the tendency manifested by droplets with appropriately small mass to take on a spherical shape.

The values of the area of droplet contact with the heating surface, measured with high accuracy, can be approximated using formula (3). For $n=2$, the formula indicates linear droplet diameter dependence on time. Figure 15 shows calculated values of droplet diameters as a function of time for the surface temperatures ranging from 300 to approx. $400{ }^{\circ} \mathrm{C}$. For the sake of calculations, the data in Fig. 11 were adopted.

As shown in Fig. 15, the slope of the droplet diameter reduction in time is decreased as the heating surface temperature grows. That results from increasingly shorter droplet

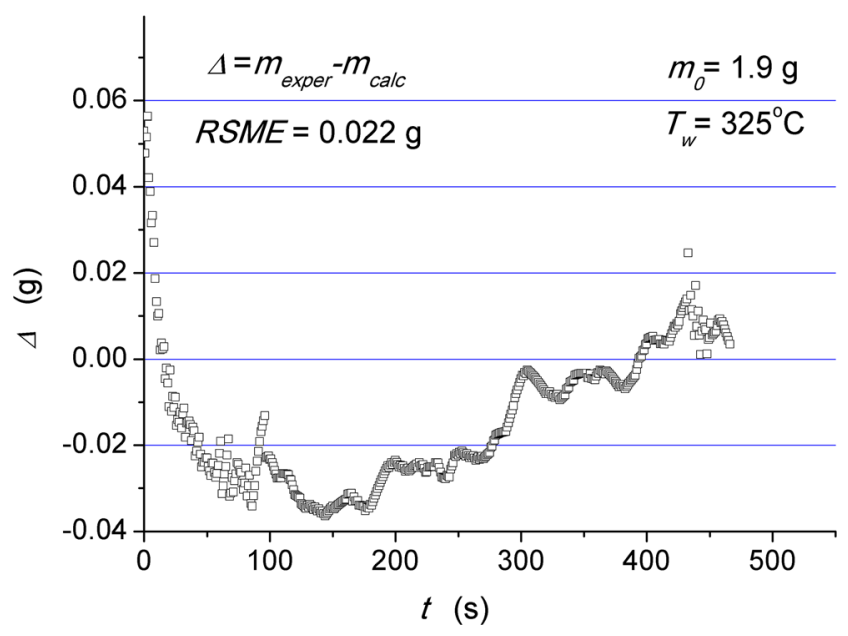

Fig. 14 Regular residuals from data in Fig. 13



Fig. 15 Droplet diameter dependence on time for different values of the heating surface

lifetime. Using the best-fit linear regression, the slope can be determined for all consecutive measurements. The values calculated in this manner are shown in Fig. 16.

Based on linear approximation (Fig. 11) of measured values of the droplet orthogonal projection as a function of droplet instantaneous mass, the value of the slope $b_{m}$, common to every heating surface temperature, is determined. Using formula (4), it is possible to calculate the coefficient of heat transfer between the heating surface and the droplet. The coefficient value varies with the contact zone and the slope, as shown in Fig. 17.

The heat transfer coefficient for large-diameter droplets $D=25 \mathrm{~mm}\left(A \approx 491 \mathrm{~mm}^{2}\right)$ ranges from 141 to $220 \mathrm{~W} / \mathrm{m}^{2} \mathrm{~K}$ as the heating surface temperature grows from 300 to $398{ }^{\circ} \mathrm{C}$. In accordance with dependence (4), the value of this coefficient grows with droplet evaporation time. For diameter $D=$ $5 \mathrm{~mm}\left(A \approx 19.6 \mathrm{~mm}^{2}\right)$, the coefficient value is about $706 \mathrm{~W} /$ $\mathrm{m}^{2} \mathrm{~K}$ at $T_{w}=300{ }^{\circ} \mathrm{C}$, and slightly over $1100 \mathrm{~W} / \mathrm{m}^{2} \mathrm{~K}$ at $T_{w}=$ $398^{\circ} \mathrm{C}$.

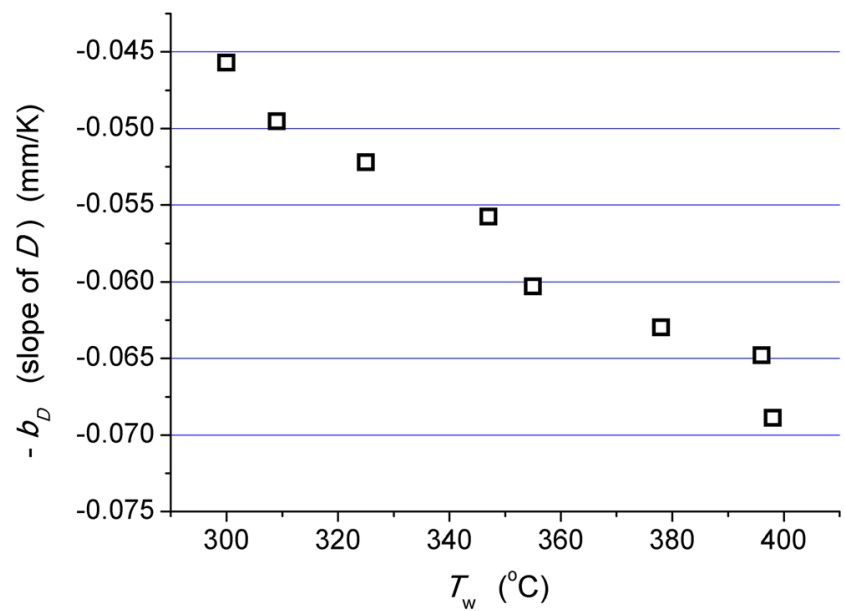

Fig. 16 Slope of droplet diameter reduction in time determined with the best-fit linear regression 


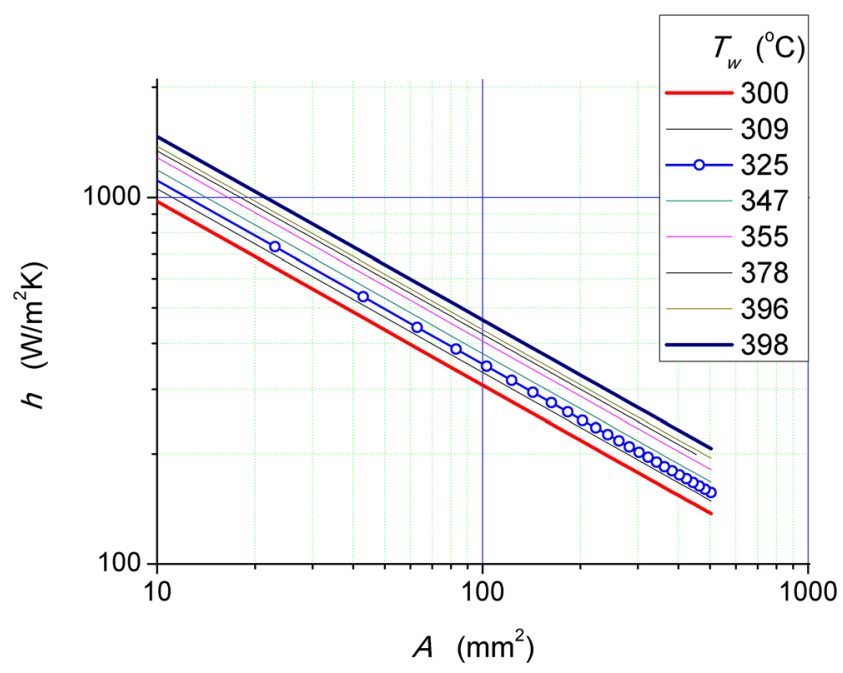

Fig. 17 Heat transfer coefficient versus droplet orthogonal projection onto the heating surface at different temperatures

The heat transfer coefficient values quoted in the literature differ significantly. For instance, in study [7], computational procedure for the determination of the temperature gradient in the vapour layer underneath the droplet is given. The computations reported in the study indicate that at heating surface temperature of $300{ }^{\circ} \mathrm{C}$, the heat transfer coefficient is $365.2 \mathrm{~W} / \mathrm{m}^{2} \mathrm{~K}$. The experimental data, however, show this value is much lower, namely only $294 \mathrm{~W} / \mathrm{m}^{2} \mathrm{~K}$. Similar discrepancies are observed when the evaporation occurs on surfaces having the shape of small-diameter spherical cap [26]. Under such circumstances, the droplet orthogonal projection is smaller than the contact zone.

The rate of the droplet mass loss depends on the heating surface temperature. The process can be quantitatively assessed by comparing the evaporation time of the identical mass at various temperatures of the heating surface. The comparison is illustrated in Fig. 18, which

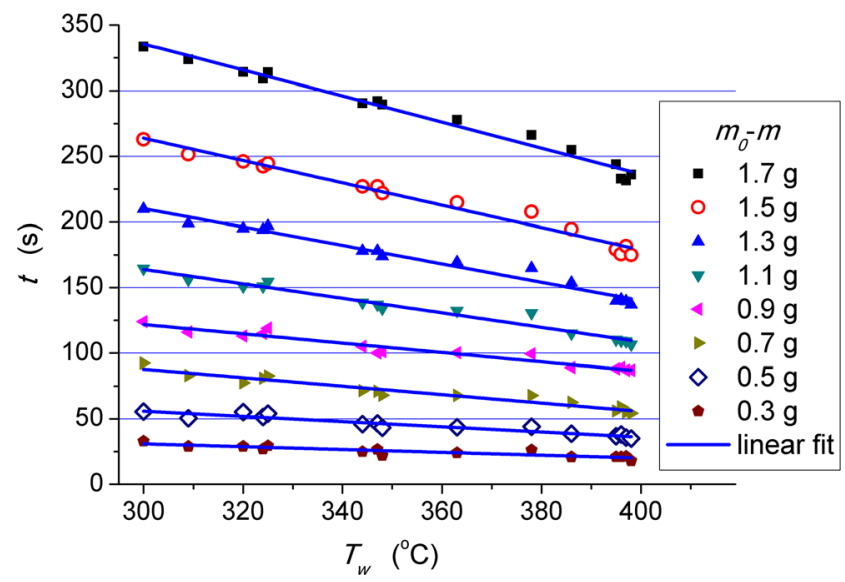

Fig. 18 Evaporation time of the same mass from droplets deposited on surfaces with different temperatures

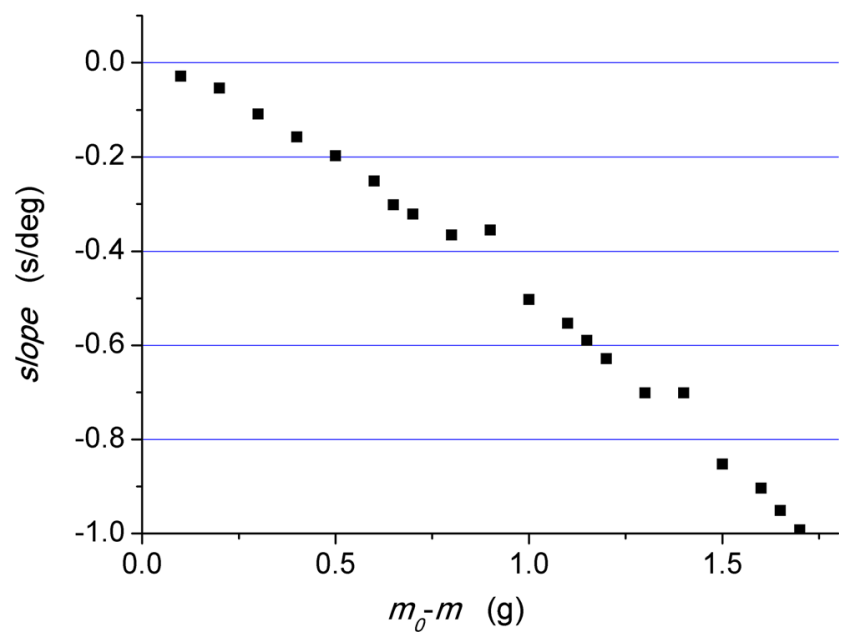

Fig. 19 Change in the slope of straight lines acc. Figure 18

shows time necessary to evaporate the same amount of mass as a function of the heating surface temperature. The points corresponding to the same amount of evaporated water are positioned along straight lines that descend with the surface temperature increase. The slope of the lines with respect to the horizontal axis decreases successively. A change in the slope gradient as a function of mass loss is shown in Fig. 19.

For water droplets levitating above the heating surface with the temperature higher than the Leidenfrost point, identical mass loss as a function of temperature is linear in character. The inclination of the line that connects points with identical mass loss as a function of temperature decreases successively with a change in the droplet mass.

\section{Conclusions}

In the droplet positioned on a hot surface, the processes of heat and mass transfer interact. Additionally, complex shape of the droplet and internal convective flows make it very difficult to provide a precise description of its behaviour. For the sake of engineering practice, the formulas that allow to estimate, accurately enough, the heat transfer coefficient and mass loss over time are sufficient. In Leidenfrost phenomenon, both quantities are closely related to each other, i.e. the amount of heat transferred determines the total mass flux from the droplet surface. Conversely, measuring mass loss, it is possible to calculate heat transferred to the environment.

The investigations, reported in the study, which concern water droplet at atmospheric pressure deposited on a hot surface with the temperature higher than the Leidenfrost point indicate distinctive features of this phenomenon: 
- Droplet orthogonal projection onto the heating surface changes linearly with the droplet mass (see Fig. 11),

- Droplet contact zone changes over time according to power dependence with the exponent $n=2$ (see Eq. 3), which is confirmed by the linear dependence of the droplet diameter on time for $D>5 \mathrm{~mm}$ (see Fig. 15),

- Heat balance was given under the assumption of that evaporation from the droplet upper surface is small compared with the amount of heat removed from the bottom surface, and overall heat transfer coefficient contains all heat exchange components (Eq. 1),

- The solution to the heat balance is a formula for the coefficient of heat transfer between the bottom of the drop and the heating surface (Eq. 4). It depends on two slope values $\left(b_{D}\right.$ and $\left.b_{m}\right)$ and an orthogonal projection of the droplet onto the heating surface.

- Evaporation of the same amount of mass decreases linearly with an increase in the heating surface temperature (see Fig. 18),

- Slope of the line that connects points with identical mass loss as a function of the heating surface temperature decreases successively from values close to zero for large droplets, and to values lower than $-1 \mathrm{~s} / \mathrm{K}$ for small droplets with the mass smaller than $0.2 \mathrm{~g}$ (see Fig. 19),

- Heat balance was given under the assumption of power dependence of heat transfer coefficient on droplet orthogonal projection onto the heating surface. The solution to the heat balance is a formula for the droplet mass change in time. The solution provides a good representation of droplet evaporation under Leidenfrost conditions, as seen in Figs. 13 and 14.

The conclusions above were formulated on the basis of measurements of changes in the droplet mass in time. The measurements were recorded at frequency of $1 \mathrm{~Hz}$ for the heating surface temperature ranging from 300 to $400{ }^{\circ} \mathrm{C}$. To visualise the droplet shape, a digital camera was positioned directly above the droplet. On the basis of the footage frames, the number of which was always higher than 60 (and in some series greater than 100), the droplet orthogonal projection onto the heating surface was determined.

For small droplets with the mass lower than $0.2 \mathrm{~g}$, the decrease in the projection area is observed to be non-linear. The probable cause of the discrepancy are successive changes in the droplet shape. With large mass, the droplet is discshaped, later on, the surface tension forces become comparable with gravitational forces and the droplet tends to take on a spherical shape.

\section{Compliance with ethical standards}

Conflict of interest The author declare that they have no conflict of interest.
Open Access This article is licensed under a Creative Commons Attribution 4.0 International License, which permits use, sharing, adaptation, distribution and reproduction in any medium or format, as long as you give appropriate credit to the original author(s) and the source, provide a link to the Creative Commons licence, and indicate if changes were made. The images or other third party material in this article are included in the article's Creative Commons licence, unless indicated otherwise in a credit line to the material. If material is not included in the article's Creative Commons licence and your intended use is not permitted by statutory regulation or exceeds the permitted use, you will need to obtain permission directly from the copyright holder. To view a copy of this licence, visit http://creativecommons.org/licenses/by/4.0/.

\section{References}

1. Baumeister KJ, Simon FF (1973) Leidenfrost temperature-its correlation for liquid metals cryogens, hydrocarbons, and water. ASME J Heat Transf 95:166-204

2. Bernardin JD, Mudawar L (1999) The Leidenfrost point: experimental study and assessment of existing models. ASME J Heat Transf 121:884-903

3. Biance AL, Clanet C, Quéré D (2003) Leidenfrost drops. Phys Fluids 15(6):1632-1637. https://doi.org/10.1063/1.1572161

4. Burton JC, Sharpe AL, Veen RCA, Franco A, Nagel SR (2012) Geometry of the vapor layer under a Leidenfrost droplet Phys. Rev Lett 109:074301. https://doi.org/10.1103/PhysRevLett.109.074301

5. Cai C, Mudawar I, Liu H, Si C (2020) Theoretical Leidenfrost point (LFP) model for sessile droplet. Int J Heat Mass Transf 146:118802

6. Chen H, Cheng W, Peng Y, Jiang L (2018) Dynamic Leidenfrost temperature increase of impacting droplets containing high-alcohol surfactant. Int J Heat Mass Transf 118:1160-1168

7. Dasgupta A, Chandraker DK, Nayak AK, Vijayan PK (2015) Prediction of vapor film thickness below a Leidenfrost drop. ASME J Heat Transf 137:124501-124505

8. Guo R, Wu J, Fan H, Zhan X, Hui Y (2016) Investigation of dissolved salts on heat transfer for aluminum alloy 2024 during spray quenching. Appl Ther Eng 107:1065-1076

9. Kang DG, Kim JH, Lee CY (2018) Minimum film boiling temperature and minimum heat flux in pool boiling of high-temperature cylinder quenched by aqueous surfactant solution. J Mech Sci Technol 32(12):5919-5926

10. Lee GC, Kang J, Park HS, Moriyama K, Kim SH, Kim MH (2017) Induced liquid-solid contact via micro/nano multiscale texture on a surface and its effect on the Leidenfrost temperature. Exp Thermal Fluid Sci 84:156-164

11. Lee GC, Noh H, Kwak HJ, Kim TK, Park HS, Fezzaa K, Kim MH (2018) Measurement of the vapor layer under a dynamic Leidenfrost drop. Int J Heat Mass Transf 124:1163-1171

12. Legros JC, Piskunov MV (2018) Evaporation of water droplets with metallic inclusions. Int J Multiph Flow 102:64-76

13. Limbeek MAJ, Schaarsberg MHK, Sobac B, Rednikov A, Sun C, Colinet P, Lohse D (2017) Leidenfrost drops cooling surfaces: theory and interferometric measurement. J Fluid Mech 827:614-639. https://doi.org/10.1017/jfm.2017.425

14. Ma Q, Wu X, Li T, Chu F (2020) Droplet boiling on heated surfaces with various wettabilities. Appl Ther Eng 167:114703

15. Misyura SY (2017) Free convection and vapor diffusion of droplet aqueous solutions. Chem Eng Res Des 126:153-160

16. Misyura SY (2018) Evaporation and heat and mass transfer of a sessile droplet of aqueous salt solution on heated wall. Int J Heat Mass Transf 116:667-674 
17. Mohapatra SS, Ravikumar SV, Jha JM, Singh AK, Bhattacharya C, Pal SK, Chakraborty S (2014) Ultra fast cooling of hot steel plate by air atomized spray with salt solution. Heat Mass Transf 50:587601. https://doi.org/10.1007/s00231-013-1260-6

18. Moita AS, Herrmann D, Moreira ALN (2014) Fluid dynamic and heat transfer processes between solid surfaces and non-Newtonian liquid droplets. Appl Ther Eng 88:33-46

19. Moon JH, Cho M, Lee SH (2016) Dynamic wetting and heat transfer characteristics of a liquid droplet impinging on heated textured surfaces. Int J Heat Mass Transf 97:308-317

20. Mozumder AK, Ullah MR, Hossain A, Islam MA (2010) Sessile droplet evaporation and Leidenfrost phenomenon. Am J Appl Sci 7(6):846-851

21. Nukiyama $S$ (1934) The maximum and minimum values of the heat Q transmitted from metal to boiling water under atmospheric pressure (tr. by C.J . Lee from l. lap. Soc. Mech. Engr. (1934) 37:367374). Int J Heat Mass Trans 9(12):1419-1433

22. Ok JT, Choi J, Brown E, Park S (2016) Effect of different fluids on rectified motion of Leidenfrost droplets onmicro/sub-micron ratchet. Microelectron Eng 158:130-134

23. Orejon D, Sefiane K, Takata Y (2014) Effect of ambient pressure on Leidenfrost temperature. Phys Rev E90(5):053012. https://doi.org/ 10.1103/PhysRevE.90.053012

24. Orzechowski T (2018) Leidenfrost evaporation of water droplet. MATEC Web Conf 240(01029). https://doi.org/10.1051/ matecconf $/ 201824001029$

25. Orzechowski T, Wciślik S (2014) Analysis of D-2-law in case of Leidenfrost drop evaporation. Exp Thermal Fluid Sci 59:230-237

26. Orzechowski T, Wciślik S (2014) Instantaneous heat transfer for large droplets levitating over a hot surface. Int J Heat Mass Transf 73:110-117

27. Ozkan O, Bahadur V (2020) Heat transfer enhancement associated with electrostatic suppression of Leidenfrost droplets. Int J Heat Mass Transf 149:119207

28. Paul G, Das PK, Manna I (2015) Droplet oscillation and pattern formation during Leidenfrost phenomenon. Exp Thermal Fluid Sci 60:346-353

29. Pomeau Y, Le Berre M, Celestini F, Frisch T (2012) The Leidenfrost effect: from quasi-spherical droplets to puddles. C R Mecanique 340:867-881

30. Qiao L, Zeng Z, Xie H, Liu H, Zhang L (2019) Modeling Leidenfrost drops over heated liquid substrates. Int J Heat Mass Transf 128:1296-1306

31. Quéré D (2013) Leidenfrost dynamics. Annu Rev Fluid Mech 45(1):197-215

32. Ravikumar SV, Jha JM, Mohapatra SS, Sinha A, Pal AS, Chakraborty S (2013) Experimental study of the effect of spray inclination on ultrafast cooling of a hot steel plate. Heat Mass Transf 49:1509-1522. https://doi.org/10.1007/s00231-013-1190-3

33. Roques-Carmes T, Domps A, Marchal P, Marchal-Heussler L (2018) Equivalent capacitive thickness of the vapor layer below
Leidenfrost drops. Exp Fluids 59(115):1-12. https://doi.org/10. 1007/s00348-018-2567-3

34. Sarkar I, Jha JM, Priyanka V, Pal SK, Chakraborty S (2019) Application of binary mixed surfactant additives in jet impingement cooling of a hot steel plate. Heat Mass Transf 55:3413-3425. https://doi.org/10.1007/s00231-019-02665-3

35. Shahriari A (2018) Electrostatic control and enhancement of film boiling heat transfer. Dissertation, University of Texas

36. Shahriari A, Ozkan O, Bahadur V (2017) Electrostatic suppression of the Leidenfrost state on liquid substrates. Langmuir 33(46): 13207-13213

37. Snoeijer JH, Brunet P, Eggers J (2009) Maximum size of drops levitated by an air cushion. Phys Rev E. https://doi.org/10.1103/ PhysRevE.79.036307

38. Tabe H, Kobayashi K, Yaguchi H, Fujii H, Watanabe M (2019) Influence of liquid-solid intermolecular force on levitation of impacting nanodroplet. Heat Mass Transf 55:993-1003. Do: https://doi.org/10.1007/s00231-018-2474-4

39. Talari V, Behar P, Lu Y, Haryadi E, Liu D (2018) Leidenfrost droplets on micro/nanostructured surfaces. Front Energy 12(1): $22-42$

40. Tiara AM, Chakraborty S, Sarkar I, Pal SK, Chakraborty S (2017) Effect of alumina nanofluid jet on the enhancement of heat transfer from a steel plate. Heat Mass Transf 53:2187-2197

41. Wang BB, Wang X-D, Wanga T-H, Lu G, Yan W-M (2017) Enhancement of boiling heat transfer of thin water film on an electrified solid surface. Int J Heat Mass Transf 109:410-416

42. Wang XW, Ho JY, Leong KC (2018) An experimental investigation of single droplet impact cooling on hot enhanced surfaces fabricated by selective laser melting. Int J Heat Mass Transf 120: 652-670

43. Wciślik S (2017) A simple economic and heat transfer analysis of the nanoparticles use. Chem Pap 71:2395-2401

44. Wua Z-H, Chang W-H, C-li S (2018) A spherical Leidenfrost droplet with translation and rotation. Int J Therm Sci 129:254-265

45. Yagov VV, Lexin MA, Zabirov AR, Kaban'kov ON (2016) Film boiling of subcooled liquids. Part I: Leidenfrost phenomenon and experimental results for subcooled water. Int. J. Heat Mass Transf 100:908-917

46. Ye S, Wu C-M, Zhang L, Li Y-R, Liu Q-S (2018) Evolution of thermal patterns during steady state evaporation of sessile droplets. Exp Thermal Fluid Sci 98:712-718

47. Yong J-Y, Kang YT (2012) Effect of surface charge state on the thermal conductivity of nanofluids. Heat Mass Transf 48:713-771

48. Zabirov A, Yagov V, Kanin P, Ryzantcev V, Vinogradov M, Molotova I (2020) Pressure influence on unsteady film boiling of water-ethanol mixtures. Exp Thermal Fluid Sci 118:110130

Publisher's note Springer Nature remains neutral with regard to jurisdictional claims in published maps and institutional affiliations. 